Relating bird host distribution and spatial heterogeneity in trematode infections in an intertidal snail - from small to large scale.

Fredensborg, Brian Lund; Mouritsen, Kim Nørgaard; Poulin, Robert

Published in:

\{MARINE BIOLOGY\}

Publication date:

2006

Citation for published version (APA):

Fredensborg, B. L., Mouritsen, K. N., \& Poulin, R. (2006). Relating bird host distribution and spatial heterogeneity in trematode infections in an intertidal snail - from small to large scale. \{MARINE BIOLOGY\}, 149. 


\section{Relating bird host distribution and spatial heterogeneity in trematode infections in an intertidal snail-from small to large scale}

Received: 25 February 2005/ Accepted: 12 September 2005 / Published online: 7 December 2005

(C) Springer-Verlag 2005

\begin{abstract}
Shorebird abundance and spatial distribution of larval trematodes in the New Zealand mudsnail, Zeacumantus subcarinatus, were investigated in soft-sediment intertidal bays within Otago Harbour, South Island, New Zealand. In a small-scale study, recruitment of trematodes to caged sentinel snails and the prevalence of infection in free-living snails were examined across a grid of fifteen $50 \times 25 \mathrm{~m}$ plots arranged in a representative area of an intertidal bay, in relation to within-plot shorebird abundance (definitive hosts) and tidal height. In a large-scale study, natural spatial variation of larval trematodes in $Z$. subcarinatus was examined across 12 bays in relation to local abundance of shorebirds. Our results revealed that trematode prevalence in snails was positively correlated with bird abundance across bays $\left(R^{2}=0.503, P=0.006\right)$. In contrast, despite a difference in bird abundance between tidal heights, there was no evidence that trematode prevalence reflected the spatial distribution of birds in the small-scale study, suggesting that factors related to differences in submersion time may override the differential input of trematode eggs from birds.
\end{abstract}

Communicated by G.F. Humphrey, Sydney

B. L. Fredensborg $(\bowtie)$

Marine Science Institute, Department of Ecology, Evolution, and Marine Biology, University of California, Santa Barbara, Santa Barbara, CA 93106-9610, USA

E-mail: fredensborg@lifesci.ucsb.edu

Fax: + 1-805-8938062

K. N. Mouritsen

Department of Marine Ecology, Institute of Biological Sciences, Aarhus University, Finlandsgade 14, 8200, Aarhus N, Denmark

R. Poulin

Department of Zoology, University of Otago, P.O. Box 56, Dunedin, New Zealand

\section{Introduction}

An increasing number of studies are focussing on explaining spatial variation in animal community structure and species richness (Blanchard and Bourget 1999; Grey 2002; Ricklefs 2004). Previously, parasitism was an overlooked biotic parameter, but its impact on host ecology is now widely accepted and has more recently been recognised as an important factor in the structure of animal communities and food webs (Minchella and Scott 1991; Mouritsen and Poulin 2002; Thompson et al. 2005). The spatial distribution of parasites is known to vary greatly between host populations (Esch and Fernandez 1993; Poulin 1998). To integrate the effect of parasites into current community structure models, it is important to understand the mechanisms underlying their recruitment into host populations.

Larval trematodes in intertidal snails are classical examples of parasites with a heterogeneous spatial variation among hosts (Curtis and Hurd 1983; Poulin and Mouritsen 2003; Fredensborg et al. 2005). For many intertidal trematodes, the life cycle includes a snail first intermediate host, a second intermediate crustacean or mollusc host, and a bird definitive host. Sexual reproduction takes place inside the gastrointestinal tract of the bird host, and trematode eggs are passed out into the external environment with the faeces of the bird. Snails subsequently get infected either by accidentally ingesting a trematode egg when feeding non-selectively on the sediment or when they are penetrated by miracidia hatched from trematode eggs. The impact of trematodes on intermediate host ecology and community structure is well documented in the intertidal ecosystem (Sousa 1991; Thomas et al. 1997; Mouritsen and Poulin 2002). However, we currently do not understand how to predict and explain spatial heterogeneity in the impact of trematodes on benthic animal communities (Poulin and Mouritsen 2003).

The high mobility of birds compared to the other hosts in the trematode life cycle makes birds the main 
dispersal agents of trematodes. The spatial distribution of bird definitive hosts is therefore naturally assumed to be responsible for the often highly heterogeneous spatial infection pattern of larval trematodes in their first intermediate hosts. In spite of this logical assumption, evidence is mostly circumstantial or indirect and based on few observational data on bird abundance (Matthews et al. 1985; Bustnes and Galaktionov 1999; Marcogliese et al. 2001; Skirnisson et al. 2004). Of the studies where bird abundance has been monitored, contrasting results have been obtained (Smith 2001; Kube et al. 2002; Latham and Poulin 2003; Hechinger and Lafferty 2005). The problems of relating bird abundance to trematode prevalence in snails are several. Most importantly, bird distribution is often highly variable in time and space, and transmission of trematode eggs from birds to snails is consequently difficult to predict at the scale at which snails are sampled. Hence, studies on large-scale patterns in trematode infection in Hydrobia spp. and on the similarly transmitted acanthocephalan parasites in shore crabs failed to demonstrate a significant relationship between parasite abundance in first intermediate hosts and the abundance of birds (Fredensborg 2001; Kube et al. 2002; Latham and Poulin 2003). In these studies, the variation in bird numbers over time was considerable within study areas. On the other hand, Smith (2001) found in a small-scale study that the recruitment of larval trematodes to the snail, Cerithidea scalariformis, was significantly related to the density of perches in a mangrove swamp used by wading birds. Further, in that study, a very predictable distribution of birds was observed due to their regular use of the same perches for roosting. Secondly, because trematode eggs can survive for extended periods of time in the external environment (McKindsey and McLaughlin 1993; Galaktionov and Dobrovolskij 2003), tidal currents, osmotic stress and desiccation may influence the distribution and survival of trematode eggs and thus affect the spatial distribution of trematodes in snails. While secondary dispersal of trematode eggs is likely to be of different importance at different spatial scales, virtually nothing is known about the fate of trematode eggs in the external environment. Finally, snail dispersal can also affect the spatial distribution of larval trematodes. This is especially relevant on a very local scale if infected snails have a different migration pattern to uninfected conspecifics (Miller and Poulin 2001), but is possibly also relevant on a regional scale for snail species utilising floating of adults as a means of dispersal.

In this study, we investigated the low-tide spatial distribution of shorebirds in relation to the spatial variation of larval trematodes in the snail host, Zeacumantus subcarinatus. Bird abundance and spatial heterogeneity of larval trematodes in snails were measured at two different spatial scales: within an intertidal bay, and among intertidal bays within the same ecosystem. A repeatability analysis was performed at both spatial scales to test the predictability of the pattern of bird distribution within the study areas. Submersion time was included in the small-scale study, to evaluate the importance of tidal height to the availability of trematode eggs to snails. The results obtained at the two different spatial scales are discussed in relation to the habitat use of shorebird definitive hosts.

\section{Materials and methods}

\section{Zeacumantus subcarinatus and its trematode parasites}

The New Zealand mudsnail, Z. subcarinatus, is a common inhabitant of soft-sediment intertidal mud flats in New Zealand, where it mainly feeds on epipelic and epiphytic diatoms. Data on laboratory-reared Z. subcarinatus and field observations reveal that this species has direct development (i.e. crawl-away larvae) (Fredensborg and Poulin 2005), and that reproduction takes place once a year during the Austral spring and summer from late October to February (B. Fredensborg, unpublished data). Based on size-frequency data from the study area, $Z$. subcarinatus has a lifespan of at least 5-6 years and reaches a maximum size of about $20 \mathrm{~mm}$ (B. Fredensborg, unpublished data). Z. subcarinatus is known to be the first intermediate host to five trematode species within the study area (Otago Harbour, New Zealand). The most common trematode is the recently discovered microphallid, Maritrema novaezealandensis (Martorelli et al. 2004; Fredensborg et al. 2005), which accounts for about $60 \%$ of all observed infections. A philophthalmid and the echinostomatid, Acanthoparyphium sp., are also relatively common while a heterophyid and Microphallus sp. are only rarely observed. The second intermediate host differs between species; however, they all utilise birds as the definitive hosts (Fig. 1). Transmission of trematode eggs to snails in all species except the philophthalmid occurs via the faeces of an infected bird. The philophthalmid differs from the others by occupying the eye of birds, and its eggs are released in the bird's lacrimal secretions (Kearn 1998). Eggs of M. novaezealandensis and Microphallus sp. need to be ingested by a snail to hatch, while eggs of the other species hatch into miracidia larvae in the external environment and actively search for a snail. Due to ethical constraints, many bird species have not been confirmed as definitive hosts for trematodes via dissections, and little is therefore known about the importance of different bird species as definitive hosts for individual trematode species. Consequently, all data on trematode prevalence were pooled across trematode species prior to analysis.

\section{Study sites}

Previously obtained data on bird distribution from 17 sites within the Otago Harbour, South Island, New Zealand were used to examine the contribution of bird abundance to large-scale spatial variation of larval 


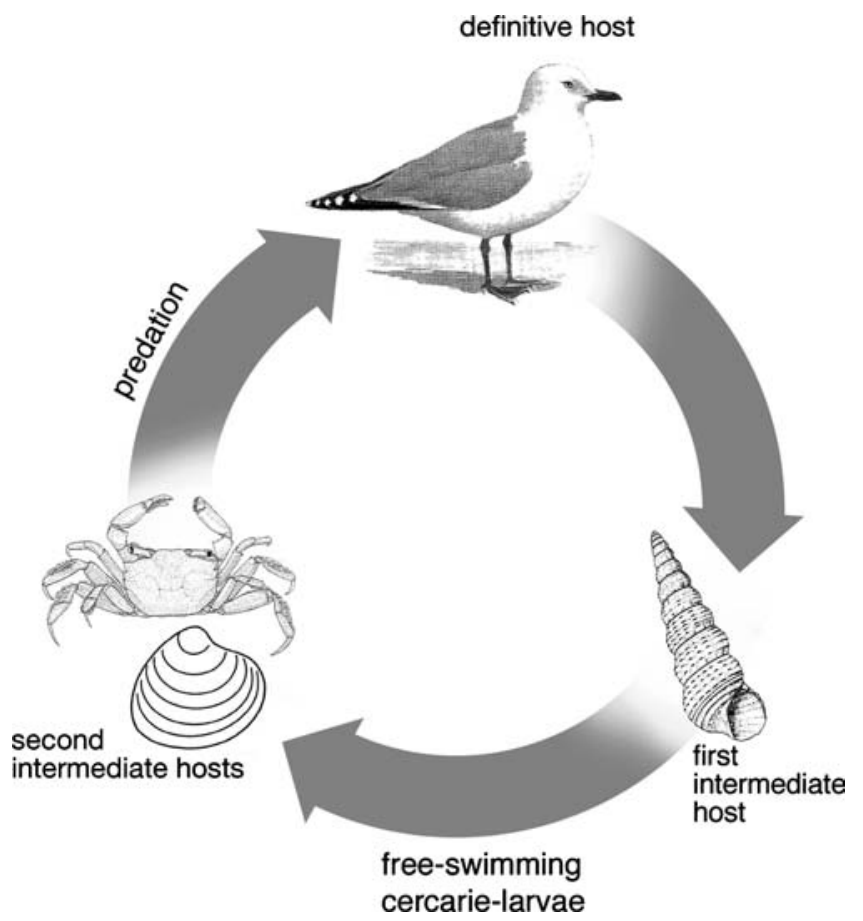

Fig. 1 Generalised life cycle for the three most common species of trematodes utilising Zeacumantus subcarinatus as the first intermediate host: Maritrema novaezealandensis (Microphallidae), Acanthoparyphium sp. (Echinostomatidae) and Philophthalmidae sp. See text for further details

trematodes in $Z$. subcarinatus. Not all of the 17 sites harboured a population of $Z$. subcarinatus and sites where birds and snails were clearly spatially segregated due to major freshwater outlets were not included in the study. A total of 12 sites, where snails could be sampled from an area representative of the bird distribution within the bay, were included in the study (Fig. 2). All sites are soft-sediment intertidal bays with similar tidal regimes (range: $2 \mathrm{~m}$ ), and submersion times (approxi- mately $16 \mathrm{~h} \mathrm{day}^{-1}$ ). There is a gradient in the sediment composition from mud flats in the inner harbour towards sand flats closer to the open ocean corresponding to increasing exposure to wave-action.

One of the 12 sites, Lower Portobello Bay, was selected for the investigation of small-scale variation in the recruitment of larval trematodes to $Z$. subcarinatus (site no. 3, Fig. 2). At this site, the upper tidal level consists mainly of slightly elevated patches of Eelgrass (Zostera novazealandica) interrupted by shallow tidal pools, with increasingly larger patches of even mud flats towards the mean low water level. Lower Portobello Bay was selected based on previous studies showing a high prevalence of larval trematodes in most size-classes of $Z$. subcarinatus, indicating a substantial recruitment of trematodes into this snail population (Fredensborg et al. 2005). For both large- and small-scale studies, our prediction is that the transmission of trematode eggs to the snail population is proportional to the number of birds visiting the site.

\section{Experimental design}

\section{Small-scale study}

In January 2003, a large sample of $Z$. subcarinatus was collected from a small island close to Oyster Bay, Otago Harbour. A preliminary investigation revealed that few snails from this population were infected by trematodes (less than 5\%, B. Fredensborg, unpublished data) making them suitable as sentinel snails for the fieldstudy on infection rates of larval trematodes. In the laboratory, these snails were individually transferred to $10 \mathrm{ml}$ petri dishes and incubated at $25^{\circ} \mathrm{C}$ for $24 \mathrm{~h}$, a method suitable to detect trematode infections as cercarial release from the snails (see Fredensborg et al. 2005). The incubation process was repeated a week later
Fig. 2 Map of study area including 12 sites within the Otago Harbour, New Zealand. Study sites are; 1: Otakou, 2: Gills corner, 3: Lower Portobello Bay, 4: Lamlash Bay, 5: Latham Bay, 6: Oyster Bay, 7: Edwards Bay, 8: Turnbull Bay, 9: Company Bay, 10: Otafelo Point, 11: Waipuna Bay, 12: Dowling Bay

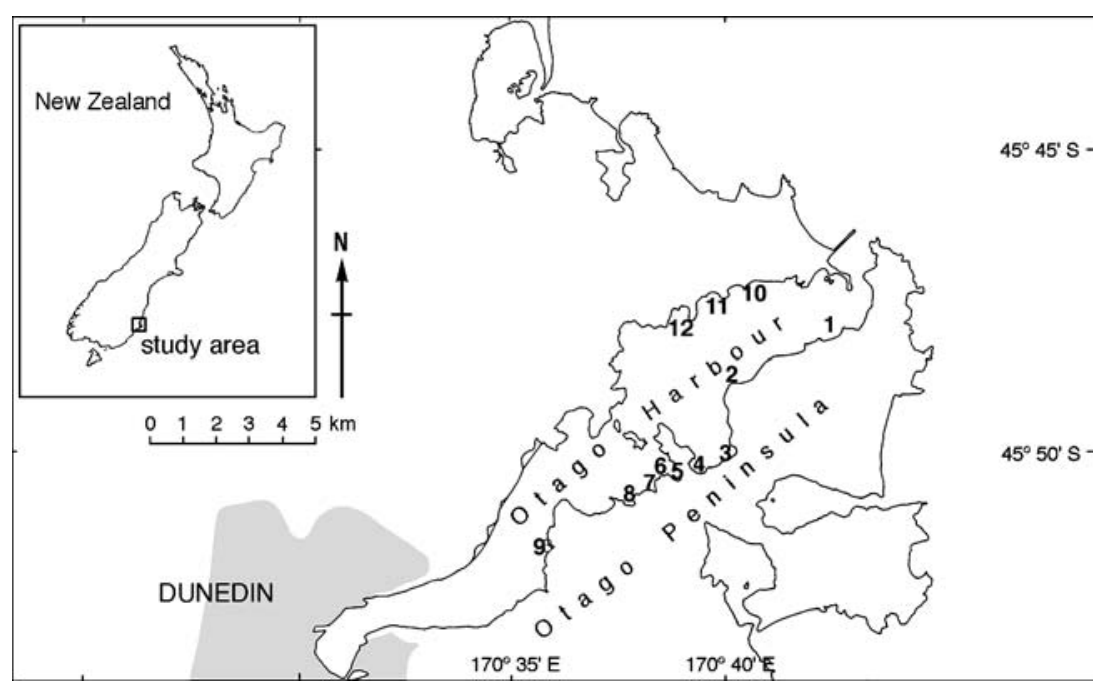


to verify whether snails were infected. After the two incubation trials, 300 individuals that were determined as uninfected (no cercarial release) were selected for the field experiment. They were measured and divided evenly into 15 groups of 20 snails, which were sizematched to avoid any size-effect on the recruitment of larval trematodes to the snails. Using naturally occurring rocks as markers, a representative area of Lower Portobello Bay was divided into 15 plots (each, $50 \times 25 \mathrm{~m}$ ). The plots were positioned in a $3 \times 5$ grid design, consisting of three tidal levels each with five plots positioned parallel to the shoreline and adjacent to one another (centre of plots positioned 50,100 and $150 \mathrm{~m}$ from the mean high water level, respectively, (width of tidal zone $=200 \mathrm{~m}$ )). A closed mesh-cage (surface area $=0.188 \mathrm{~m}^{2}, 3 \mathrm{~mm}$ mesh size) containing 20 sentinel snails was placed in the centre of each of the 15 plots. The cages were left for 4 months from early February to early June (late Austral summer and autumn), in which period the cages were regularly checked and cleaned from drifting macroalgae. At the conclusion of the experiment, the surviving snails were transferred to the laboratory, dissected and examined under a dissection microscope to assess the recruitment rate of larval trematodes to snails from each of the 15 plots. In addition, to compare the natural spatial variation of trematode prevalence in $Z$. subcarinatus within the study area, another 20 snails were randomly collected by hand from near the centre of each plot and examined for trematode infections under a dissection microscope.

During 15 low tides (between early February and mid-May), all birds inside the plots were counted from the shoreline and identified according to Heather and Robertson (2000). The counting started when the cages in the first tidal level were exposed to air and ended when they were re-submersed. Monitoring effort was highest in February and March reflecting the higher bird abundance in late summer. Birds were counted in time intervals of 5-20 min, depending on the activity of birds in the study area. Bird abundance was measured as the total number of bird minutes per plot per low tide.

\section{Large-scale study}

To determine trematode prevalences across snail populations, samples of $Z$. subcarinatus were randomly collected from a representative part of the bay (approximately $50 \times 50 \mathrm{~m}$, at mid-tide level) from six sites in the Otago Harbour in September 2002 (see Fredensborg et al. 2005 for sampling method). An additional three sites were included in September 2003, and three sites in September 2004 using identical sampling methods. For each site, the shell-height of snails was measured and snails larger than $6.0 \mathrm{~mm}$ were dissected and examined for the presence of larval trematodes. Preliminary studies indicated that trematode prevalence in $Z$. subcarinatus varied very little between years and seasons (B. Fredensborg, unpublished data). To test this assumption, a re-sampling of snails was conducted from seven sites in April 2004.

Bird abundance on a large scale was measured during regular visits to each site throughout a calendar year (April 2001-April 2002, $n=15-24$ visits per site). All visits were conducted during low tide, and the numbers of birds were counted once per site per visit.

\section{Data analysis}

In the small-scale study, the spatial distribution of birds was tested using a two-way ANOVA on Log $(x+1)$ transformed mean bird abundance per plot per observation date, with tidal height and distance along the shoreline as the two fixed factors. Spatial distribution of trematode prevalences in samples of sentinel and freeliving snails from the 15 plots were, similarly to bird abundance, tested between tidal heights and along the shoreline using Chi-square tests of association. In addition, a Pearson correlation was used to examine the relationship between mean bird abundance and trematode prevalence in snails across all 15 plots.

In the large-scale study, a correlation analysis between trematode prevalence in snails sampled in September and April showed almost identical trematode prevalences between seasons $\left(r^{2}=0.98\right)$. All data on trematode prevalence in $Z$. subcarinatus between dates were therefore subsequently pooled before further analysis. Because of a roughly constant trematode prevalence over the year, bird abundance for each site was pooled across the year and entered in the analysis as the mean number of birds per hectare per observation.

In order to investigate the relationship between bird abundance and trematode prevalence among sites, a linear regression analyses was carried out, in which trematode prevalence was entered as the dependent variable and with mean bird abundance as the predictor variable.

To test the predictability in bird abundance among plots in the small-scale study and among sites in the large-scale study, a repeatability analysis was performed following the method used by Arneberg et al. (1997) and Poulin and Mouritsen (2003). For both spatial scales, an ANOVA on $(\log x+1)$-transformed number of birds per hectare per observation, was carried out, with plots (1-15) or sites (1-12) as the class variable. A significant difference in bird abundance would indicate that the bird counts are repeatable within sites, i.e. they are more similar to each other than to counts from other sites. Furthermore, the proportion of the total variance attributed to variation among sites, rather than within sites, was estimated using the coefficient of intraclass correlation, $r_{I}$ (Sokal and Rohlf 1995, p 214). The statistical packages SPSS for Windows (10.1), and Statistica (6.0) were used for analyses and results were considered significant at $P<0.05$. 


\section{Results}

Small-scale study

Ten bird species occurred regularly within the plots in Lower Portobello Bay during the study (Table 1). Of these, the red-billed gull, (Larus novaehollandiae scopulinus) was the most abundant species with up to 400 individuals present at one time. Tidal height had a significant effect on bird abundance within the study area, while no effect of distance along the shoreline could be detected (Table 2). Post hoc comparisons showed that the lowest tidal level had a significantly lower abundance of birds compared to the two higher levels (Tukeýs test, $P=0.001$, and $P=0.005$, for comparisons with levels 1 and 2, respectively), whereas the upper two tidal levels had a very similar bird abundance $(P=0.914)$. At least part of the difference between high- and low-tidal levels was caused by a shorter exposure time during low tide: the average $( \pm \mathrm{SE})$ exposure time for the 3 tidal levels based on 14 observation dates was $202 \pm 13,139 \pm 21$ and $81 \pm 15 \mathrm{~min}$ per low tide, respectively. The repeatability analysis on bird abundance revealed that the variance within plots, from one observation day to the next, was as large as the variation among plots $\left(F_{14,224}=1.236, P=0.251, r_{\mathrm{I}}=0.016\right.$, Fig. 3a). Hence, only $1.6 \%$ of the variation in bird abundance was associated with differences among plots, rather than with differences among observations within plots. Bird abundance among observation days within plots was thus not more similar than expected by chance alone.

A total of 140 snails were recovered from the 15 cages after 5 months. Subsequent dissections showed that 13 of those $(9.28 \%)$ were infected by one of the three trematodes, M. novaezealandensis, Acanthoparyphium sp. or Philophthalmidae sp. Recruitment of trematodes to sentinel snails did not differ along the shoreline (Chisquare test: $\left.\chi^{2}=7.200, d f=4, P=0.126, N=140\right)$. Likewise, the prevalence of trematode infections in sentinel snails was not significantly different between tidal heights (Chi-square test: $\chi^{2}=4.705, d f=2, P=0.095$, $N=140$ ). There was no significant correlation between mean bird abundance and the proportion of infections in sentinel snails across plots $(r=-0.43, n=5, P=0.113)$. Samples of 20 snails collected outside the cages from the 15 plots all showed a high prevalence (range: $65-100 \%$ per plot). As was observed for sentinel snails, no difference in trematode prevalence could be detected along the shoreline (Chi-square test: $\chi^{2}=3.851, \quad d f=4$,

Table 1 List of bird species observed in the small- and large-scale studies

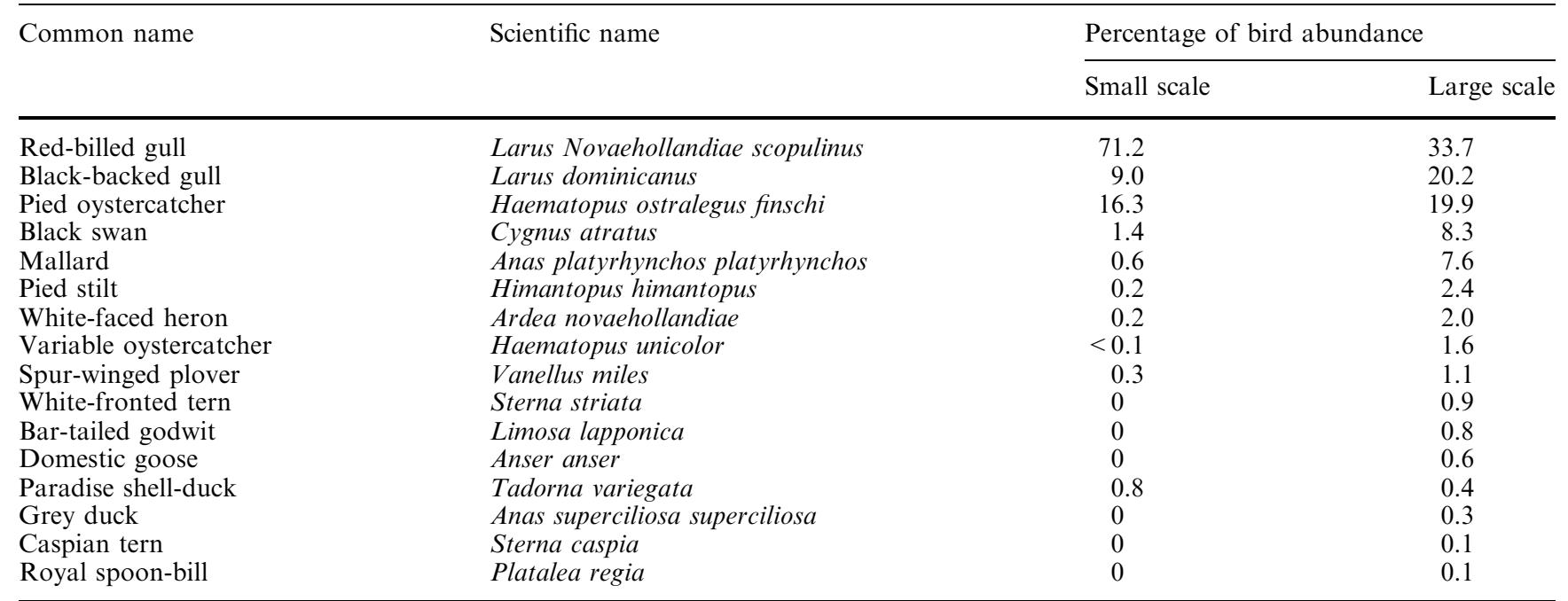

For each scale the percentage of the total bird abundance is indicated for each species. Bird abundance is for the small-scale study measured as mean number of bird minutes per plot per low tide, and for the large-scale study as mean number of birds per site per observation. Bird species are ranked in decreasing order according to their abundance in the Otago Harbour

Table 2 Results of a two-way ANOVA, evaluating the abundance of shorebirds in relation to tidal height and distance along the shoreline within Lower Portobello Bay. Data were Log $(x+1)$ transformed

\begin{tabular}{|c|c|c|c|c|c|}
\hline Factor & $d f$ & SS & MS & $F$ ratio & $P$ value \\
\hline Tidal height & 2 & 12.981 & 6.490 & 7.509 & 0.001 \\
\hline Shoreline & 4 & 0.673 & 0.168 & 0.195 & 0.941 \\
\hline Interaction & 8 & 1.308 & 0.164 & 0.189 & 0.992 \\
\hline Error & 210 & 181.520 & 0.864 & & \\
\hline
\end{tabular}


Fig. 3 Rank plots of observation sites and bird abundance. Sites are ranked according to their mean logtransformed values of either number of bird minutes (a) or number of birds (b), with Rank 1 given to the site with the lowest mean value. a Sites represent the 15 plots within Lower Portobello Bay. b Sites represent the 12 localities (see Fig. 2) from which birds were monitored within the Otago Harbour
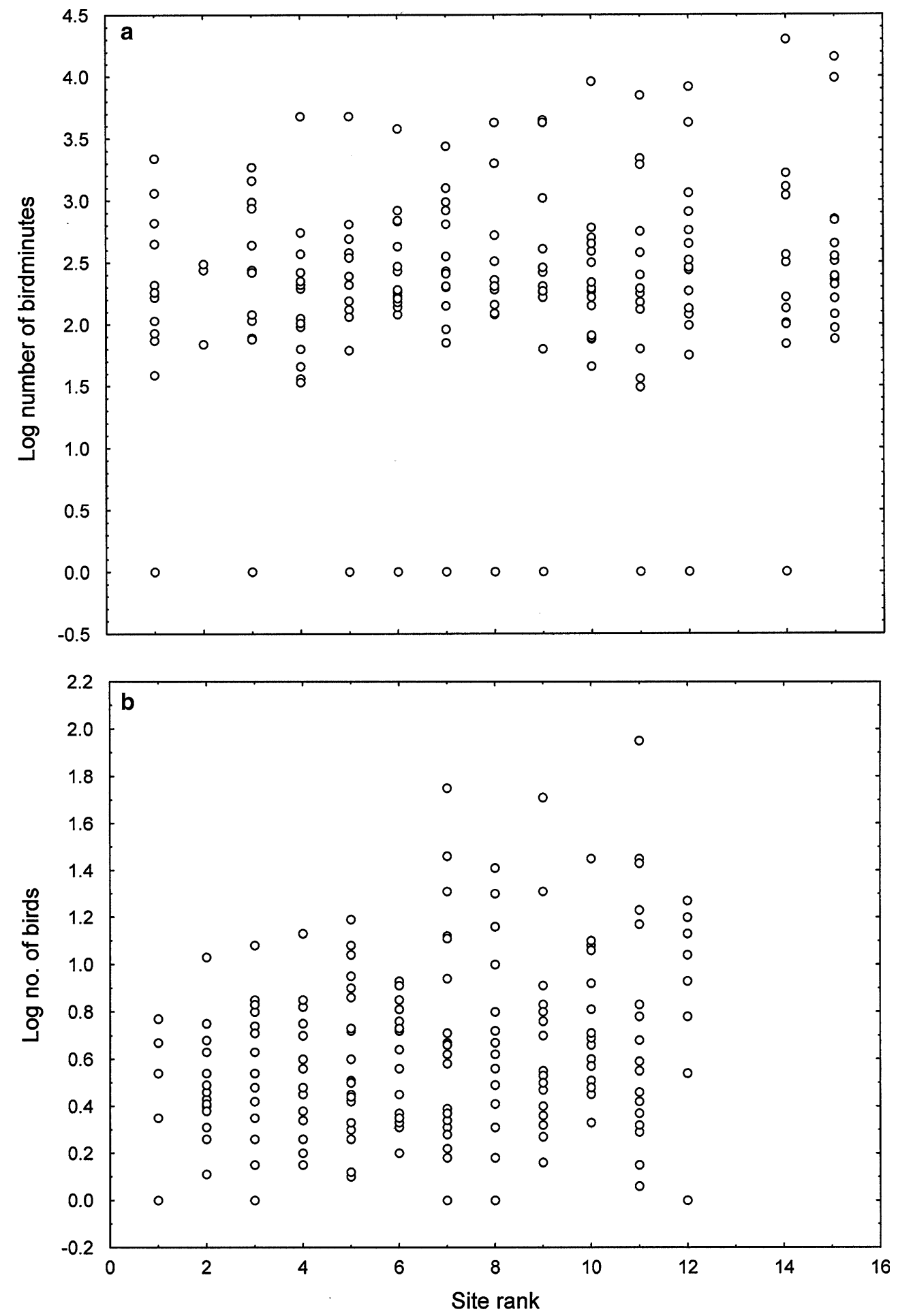

$P=0.427, N=299$ ). The prevalence in free-living snails was not significantly different between tidal heights (Chisquare test: $\chi^{2}=4.896, d f=2, P=0.086, N=299$ ). There was no relationship between mean bird abundance and trematode prevalence in free-living snails across the 15 plots $(r=0.06, n=15, P=0.84)$.

\section{Large-scale study}

A total of 16 bird species were observed over a year within 12 sites in the Otago Harbour (Table 1). Similar to the small-scale study, the most common bird in the Otago Harbour area was the red-billed gull 
(L. novaehollandiae scopulinus), accounting for approximately a third of all observations. Bird abundance varied greatly between dates as well as sites. However, the repeatability analysis indicated that the number of birds at any given site was more similar across dates than expected by chance alone $\left(F_{12}\right.$, $269=9.033, P<0.001, r_{\mathrm{I}}=0.06$, Fig. $3 \mathrm{~b}$ ), although the variance between sites only accounted for approximately $6 \%$ of the variation among observations. This result indicates that bird numbers, although variable in space and time, show a long-term pattern in their distribution within the Otago Harbour.

Trematode prevalence in $Z$. subcarinatus also differed greatly between sites (Table 3 ). A linear regression with trematode prevalence as the dependent variable and mean bird abundance as the predictor variable showed a highly significant and positive linear relationship between mean bird abundance and trematode prevalence across sites $\left(F_{1,11}=12.155, P=0.006, R^{2}=0.503\right)$. The exclusion of the strictly piscivorous terns and the herbivorous black swan from the analysis further strengthened this relationship $\left(F_{1,11}=18.574, P=0.002\right.$, $R^{2}=0.615$, Fig. 4)

To investigate which bird species were mainly responsible for the observed relationship between bird abundance and prevalence in snails, birds were entered into four groups: 1) Laridae, 2) waders feeding mainly on infauna, 3) waders feeding mainly on epifauna and 4) Anseriformes. Of these four groups, only Laridae explained a significant amount of the variation in trematode prevalence among sites $\left(F_{1,11}=16.661, P=0.002\right.$, $R^{2}=0.587$ ).

Table 3 List of site characteristics used in a linear regression analysis to examine the importance of bird abundance on the variation in trematode prevalence among sites

\begin{tabular}{lccc}
\hline Site & $\begin{array}{c}\text { Trematode } \\
\text { prevalence }\end{array}$ & $n$ & $\begin{array}{l}\text { Bird abundance } \\
\left(\text { mean ha }^{-1} \text { obs }^{-1} \text { ) }\right.\end{array}$ \\
\hline Otakou & 13.3 & 210 & $7.03 \pm 1.42$ \\
Gill's Corner & 73.0 & 111 & $10.42 \pm 4.47$ \\
Lower Portobello Bay & 89.4 & 350 & $7.17 \pm 2.72$ \\
Lamlash Bay & 26.4 & 144 & $3.92 \pm 0.83$ \\
Latham Bay & 11.1 & 370 & $5.90 \pm 2.10$ \\
Oyster Bay & 56.6 & 442 & $9.65 \pm 1.34$ \\
Edwards Bay & 13.0 & 138 & $2.07 \pm 0.36$ \\
Turnbull Bay & 8.70 & 230 & $2.89 \pm 0.61$ \\
Company Bay & 29.8 & 262 & $4.97 \pm 1.22$ \\
Otafelo Point & 2.0 & 98 & $5.17 \pm 0.52$ \\
Waipuna Bay & 1.0 & 200 & $3.95 \pm 0.60$ \\
Dowling Bay & 4.5 & 333 & $3.94 \pm 0.64$ \\
$P$ value & $<0.001$ & & $<0.001$ \\
\hline
\end{tabular}

${ }^{\text {a }}$ Trematode prevalence among snail populations was tested using a Chi-square testBird abundance among sites was tested using a oneway ANOVA

Bird abundance data are given as mean \pm SE. Trematode prevalence was determined by dissection of snails $>6.0 \mathrm{~mm}$ obtained from quantitative and qualitative sampling (see text for details). $n$ indicates the sample size of snails dissected and examined for larval trematodes. Bird abundance was observed as one count per observation day ( $n=15-24$ observation days per site)

\section{Discussion}

Our results on large-scale variation in trematode prevalence among populations of $Z$. subcarinatus clearly demonstrate a positive relationship between bird abundance and trematode prevalence across snail populations within the Otago Harbour. Such a result was expected due to the fact that birds are the definitive hosts of all trematode species inhabiting $Z$. subcarinatus. Nonetheless, this study provides one of only a few robust documentations of a direct link between bird abundance and parasite spatial heterogeneity (Smith 2001; Hechinger and Lafferty 2005).

The results obtained for the two different spatial scales in this study emphasise the importance of the spatial unit under investigation for the predictability in bird distribution and trematode prevalence in snails. The relationship between bird abundance and trematode prevalence seen among bays was thus not clear on the within-bay scale, indicating that the operational factors creating spatial heterogeneity in trematode distribution have different importance at different scales. In the small-scale study, birds spent significantly less time foraging at the lowest tidal level compared to the two higher positioned levels, and a lower trematode prevalence in snails from lower tidal areas was therefore expected. Samples of free-living snails showed a similar but non-significant pattern to bird abundance, whereas sentinel snails from high and low tidal levels had very similar recruitments of trematodes. The discrepancy between the pattern of bird distribution and trematode prevalence in snails suggests that other factors differing between tidal levels may influence the transmission of trematode eggs to snails. One possible explanation could be that the longer submersion time at the lowest tidal level allows snails to increase the time spent foraging compared to higher tidal levels. A smaller input of trematode eggs would therefore be compensated for by higher snail activity, which could increase the chance of accidentally ingesting a trematode egg (see Snyder and Esch 1993). Other factors such as secondary dispersal of trematode eggs by tidal currents and, for the free-living snails, migration between tidal levels are also possible explanations.

The recuitment rate of larval trematodes to sentinel snails of about $9 \%$ seems low compared to the high prevalence observed in free-living snails. Those results suggest that the recruitment rate of trematodes to snails is low, and that the high prevalence of trematodes in snail populations therefore is the result of a slow accumulation of infections over the lifespan of the snail (Curtis 1996). Alternatively, the low recruitment rate of trematode infections to snails could be that we used adult sentinel snails which may be less susceptible to infection than younger conspecifics (Anderson and Crombie 1984).

A potentially important problem to small-scale studies on spatial heterogeneity of trematodes in the 
Fig. 4 Relationship between trematode prevalence and bird abundance across 12 sites within the Otago Harbour. Bird abundance data represent the mean number of birds per hectare per observation $(n=15-24$ observations per site)

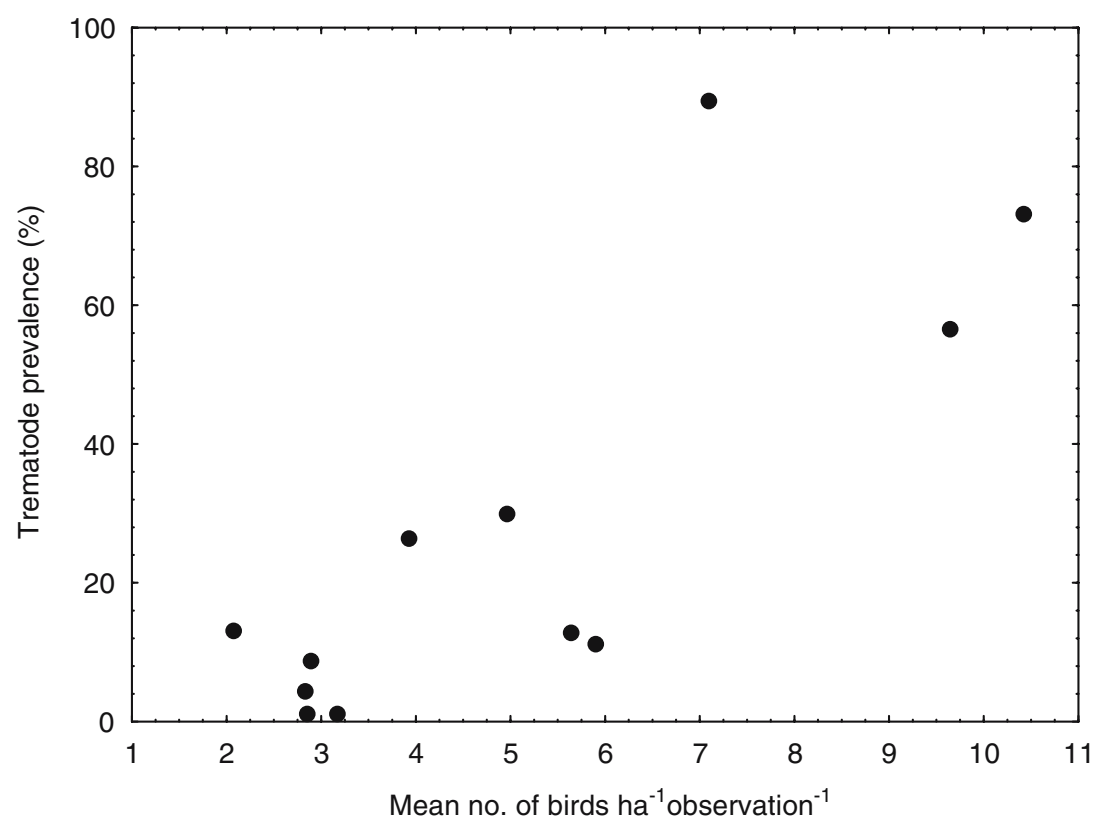

intertidal zone is associated with the foraging behaviour of birds. Availability of prey is not only dependent on prey abundance but also on the activity of prey and the penetrability of the sediment (Mouritsen and Jensen 1992). The two latter properties are often higher when the water content of the sediment is increased (Granadeiro et al. 2004). In this study birds were often observed feeding close to the tide line, and the same birds were observed foraging at all three tidal levels in accordance with ebbing and rising tides. As a result only $1.6 \%$ of the overall variation in mean bird abundance among plots in the small-scale study could be explained by differences among plots. Physical habitat features can thus explain the strikingly different results obtained by Smith (2001). In her study, the presence of dead trees serving as perches constrained the spatial distribution of birds, making it predictable and repeatable over time. The lack of such physical structures on intertidal flats could explain the variation in bird distributions.

The variability in bird abundance within sites between observations in the large-scale study was also high. However, the 1-year bird survey did reveal a consistent long-term pattern in bird distribution among sites, which was reflected in the spatial distribution of trematodes in $Z$. subcarinatus within the Otago Harbour. Thus, on an among-bay scale, bird abundance is a good predictor of spatial heterogeneity of trematodes in snails and the potential effect of trematodes on the animal benthic community in this system.

Little is known about the importance of different bird species as definitive hosts and thus dispersal agents for trematodes within the study area (McKenna 1998; Latham and Poulin 2002; Fredensborg et al. 2004a). Dividing all bird species potentially feeding on trematode second intermediate hosts into more specialised feeding guilds therefore seemed to be the best way to assess the importance of different groups of birds to the distribution of larval trematodes in Z. subcarinatus. The finding that gulls explained the largest proportion of the variation in trematode prevalence between snail populations is supported by a previous study confirming the red-billed gull as a definitive host of the microphallid, $M$. novaezealandensis, the most abundant trematode in the study area (Fredensborg et al. 2004). Studies from other geographical areas have previously recognised the importance of gulls as dispersal agents of trematodes, which have been based on higher infection rates of intermediate hosts living adjacent to breeding colonies or close to important feeding and roosting grounds of gulls (Lauckner 1987; Bustnes and Galaktionov 1999; Galaktionov and Bustnes 1999; Marcogliese et al. 2001).

In conclusion, it was found that variation in bird abundance explained a significant amount of the variation in the spatial distribution of larval trematodes among sites within the Otago Harbour. Repeatability analyses of bird abundance within and among intertidal bays indicated that a consistent pattern in the distribution of birds at the scale at which snails are collected is necessary to explain spatial heterogeneity of larval trematodes in first intermediate snail hosts. Future studies should therefore focus on developing spatial models to better predict habitat use by shorebirds.

Acknowledgements We would like to thank K. Holmes and K. Miller for technical assistance and M. Hardman for comments on an earlier draft. This study was supported by the University of Otago Research Committee, by means of the University of Otago Bridging Grant to B.L.F., by the Marsden Fund to R.P. and by The Danish Natural Science Council and the Carlsberg Foundation to K.N.M. The work in this study follows the guidelines of the University of Otago's Animal Ethics Committee. 


\section{References}

Anderson RM, Crombie J (1984) Experimental studies of ageprevalence curves for Schistosoma mansoni infections in populations of Biomphalaria glabrata. Parasitology 89:79-104

Arneberg P, Skorping A, Read AF (1997) Is population density a species character? Comparative analyses of the nematode parasites of mammals. Oikos 80:289-300

Blanchard D, Bourget E (1999) Scales of coastal heterogeneity: influence on intertidal community structure. Mar Ecol Prog Ser 179:163-173

Bustnes JO, Galaktionov K (1999) Anthropogenic influences on the infestation of intertidal gastropods by seabird trematode larvae on the southern Barents Sea coast. Mar Biol 133:449-453

Curtis LA (1996) The probability of a marine gastropod being infected by a trematode. J Parasitol 82:830-833

Curtis LA, Hurd LE (1983) Age, sex and parasites: spatial heterogeneity in a sandflat population of Ilyanassa obsoleta. Ecology 64:819-828

Esch GW, Fernandez JC (1993) A functional biology of parasitism: Ecological and evolutionary implications. Chapman and Hall, London

Fredensborg BL (2001) Dynamics of microphallid trematodes in the intermediate hosts Hydrobia ulvae and Corophium volutator during autumn. MSc thesis, Institute of Biology, Department of Marine Ecology, University of Aarhus, Denmark

Fredensborg BL, Latham AD, Poulin R (2004) New records of gastrointestinal helminths from the red-billed gull (Larus novaehollandiae scopulinus). NZ J Zool 31:75-80

Fredensborg BL, Poulin R (2005) Parasitism shaping host life history evolution: adaptive responses in a marine gastropod to infection by trematodes. J Anim Ecol (in press)

Fredensborg BL, Mouritsen KN, Poulin R (2005) Impact of trematodes on host survival and population density in the intertidal gastropod Zeacumantus subcarinatus. Mar Ecol Prog Ser 290:109-117

Galaktionov KV, Bustnes JO (1999) Distribution patterns of marine digenean larvae in periwinkles along the southern coast of the Barents Sea. Dis Aquat Org 37:221-230

Galaktionov KV, Dobrovolskij AA (2003) The biology and evolution of trematodes. Kluwer, Dordrecht

Granadeiro JP, Andrade J, Palmeirim JM (2004) Modelling the distribution of shorebirds in estuarine areas using generalized additive models. J Sea Res 52:227-240

Grey JS (2002) Species richness of marine soft sediments. Mar Ecol Prog Ser 244:285-297

Heather B, Robertson H (2000) The field guide to birds of New Zealand. Viking, Auckland

Hechinger RF, Lafferty KD (2005) Host diversity begets parasite diversity: bird final hosts and trematodes in snail intermediate hosts. Proc R Soc Lond B 272:1059-1066

Kearn GC (1998) Parasitism and the platyhelminths. Chapman and Hall, London

Kube J, Kube S, Dierschke V (2002) Spatial and temporal variations in the trematode component community of the mudsnail Hydrobia ventrosa in relation to the occurrence of waterfowl as definitive hosts. J Parasitol 88:1075-1086

Latham ADM, Poulin R (2002) New records of gastrointestinal helminths from the southern black-backed gull (Larus dominicanus) in New Zealand. NZ J Zool 29:253-257
Latham ADM, Poulin R (2003) Spatiotemporal heterogeneity in recruitment of larval parasites to shore crab intermediate hosts: the influence of shorebird definitive hosts. Can J Zool 81:12821291

Lauckner G (1987) Ecological effects of larval trematode infestations on littoral marine invertebrate populations. Int J Parasitol 17:391-398

Marcogliese DJ, Compagna S, Bergeron E, McLaughlin JD (2001) Population biology of eyeflukes in fish from a large fluvial ecosystem: the importance of gulls and habitat characteristics. Can J Zool 79:1102-1113

Martorelli SR, Fredensborg BL, Mouritsen KN, Poulin R (2004) Description and proposed life cycle of Maritrema novaezealandensis $\mathrm{n}$. sp. (Microphallidae) parasitic in red-billed gulls Larus novaehollandiae scopulinus from Otago Harbor, South Island, New Zealand. J Parasitol 90:272-277

Matthews PM, Montgomery WI, Hanna REB (1985) Infestation of littorinids by larval Digenea around a small fishing port. Parasitology 90:277-287

McKenna PB (1998) Checklist of helminth and protozoan parasites of birds in New Zealand. Surveillance 25:3-12

McKindsey CW, McLaughlin JD (1993) The viability of Sphaeridiotrema pseudoglobulus (Digenea) eggs following cold water storage as a possible overwintering strategy. Parasitology 107:441-447

Miller AA, Poulin R (2001) Parasitism, movement, and distribution of the snail Diloma subrostrata (Trochidae) in a soft-sediment intertidal zone. Can J Zool 79:2029-2035

Minchella DJ, Scott ME (1991) Parasitism: a cryptic determinant of animal community structure. Trends Ecol Evol 6:250-254

Mouritsen KN, Jensen KT (1992) Choice of microhabitat in tactile foraging dunlins Calidris alpina: the importance of sediment penetrability. Mar Ecol Prog Ser 85:1-8

Mouritsen KN, Poulin R (2002) Parasitism, community structure and biodiversity in intertidal ecosystems. Parasitology 124:S101-S117

Poulin R (1998) Evolutionary ecology of parasites: from individuals to communities. Chapman and Hall, London

Poulin R, Mouritsen KN (2003) Large-scale determinants of trematode infections in intertidal gastropods. Mar Ecol Prog Ser 254:187-198

Ricklefs RE (2004) A comprehensive framework for global patterns in biodiversity. Ecol Lett 7:1-15

Skirnisson K, Galaktionov K, Kozminsky EV (2004) Factors influencing the distribution of digenetic trematode infections in a mudsnail (Hydrobia ventrosa) population inhabiting salt marsh ponds in Iceland. J Parasitol 90:50-59

Smith NF (2001) Spatial heterogeneity in recruitment of larval trematodes to snail intermediate hosts. Oecologia 127:115-122

Snyder SD, Esch GW (1993) Trematode community structure in the pulmonate snail, Physa gyrina. J Parasitol 79:205-215

Sokal RR, Rohlf FJ (1995) Biometry, 3rd edn WH Freeman, New York

Sousa WP (1991) Can models of soft-sediment community structure be complete without parasites? Am Zool 31:821-830

Thomas F, Cézilly F, De Meeüs T, Crivelli A, Renaud F (1997) Parasitism and ecology of wetlands: a review. Estuaries 20:646654

Thompson RM, Mouritsen KN, Poulin R (2005) Importance of parasites and their life cycle characteristics in determining the structure of a large marine food web. J Anim Ecol 74:77-85 